\title{
A política pública de ensino superior para povos indígenas no Paraná: trajetórias, desafios e perspectivas
}

\section{Public policies in higher education for the indigenous peoples of the state of Paraná, Brazil: trajectories, challenges and perspectives}

\author{
Wagner Roberto do Amaral ${ }^{*}$ \\ Tânia Maria Baibich**
}

Resumo: $\mathrm{O}$ artigo reflete sobre a experiência de ingresso e permanência de estudantes indígenas nas instituições de Ensino Superior públicas do Paraná enquanto promotora de uma política pública de educação superior no território paranaense. Inspira-se nas trajetórias desses acadêmicos, ingressantes pelo Vestibular dos Povos Indígenas, demonstrando que a permanência desses sujeitos no ensino superior somente se faz possível mediante a efetivação de um duplo pertencimento: o acadêmico e étnico-comunitário. São evidentes os limites da tarefa do Estado nessa ação, uma vez que a permanência requer políticas públicas de educação superior voltadas efetivamente a esses sujeitos e sensíveis aos pertencimentos por eles construídos. O trabalho resultou de revisão de literatura, análise documental e análise de conteúdo de entrevistas realizadas junto aos acadêmicos indígenas e profissionais índios recém-formados. Reconhece-se o ineditismo da experiência paranaense iniciada nesta década, cuja consolidação se deve à efetiva atuação do Estado, das universidades públicas e das lideranças e comunidades indígenas.

Palavras-chave: Educação superior. Ações afirmativas. Povos indígenas.

\begin{abstract}
The experience on the admittance and permanence of indigenous students in public higher education institutions which are the promoters of public policy in higher education in the state of Paraná, Brazil, is provided. Current article is based on the indigenous students' trajectories at the state universities of Paraná when they were admitted through the Indigenous Entrance Exam. In fact, their permanence in higher education institutions has been possible due to the dual belonging of schooling and ethnicity. It highlights the limits of the State's role in this policy since their permanence requires higher education policies actually aimed at these subjects and sensitive to the traits built by them. Current analysis is the product of a review of the literature,
\end{abstract}

\footnotetext{
* Docente da Universidade Estadual de Londrina. E-mail: <wramaral2011@hotmail.com>

** Docente da Universidade Federal do Paraná. E-mail: <tbaibich@terra.com.br>
} 
document analysis and content analysis of interviews with indigenous students and recently graduated indigenous professionals. The uniqueness of the experience in the state of Paraná in the last decade is acknowledged. In fact, its consolidation has been foregrounded on the effective action by the above-mentioned state, by government-run universities and by indigenous leaders and communities.

Keywords: Higher Education. Affirmative actions. Indigenous peoples.

\section{Introdução}

A presença dos acadêmicos indígenas nas universidades públicas se constitui num fenômeno recente no Brasil, levado a efeito principalmente na última década, em decorrência da progressiva ampliação da escolarização de crianças, jovens e adultos em terras indígenas. Esse fenômeno vem se tornando uma realidade em vista do reconhecimento da Educação Escolar Indígena na Lei de Diretrizes e Bases da Educação Nacional de 1996, no Plano Nacional de Educação de 2001 e nas Diretrizes Nacionais da Educação Escolar Indígena no Brasil, e está associado às discussões e experiências de implantação das cotas para estudantes negros, oriundos de escolas públicas e para indígenas nas universidades públicas.

A aprovação da Lei Estadual n. ${ }^{\circ}$ 13.134, de 18 de abril de 2001 (PARANÁ, 2001), garantindo, ineditamente no país, vagas suplementares nas universidades $\mathrm{e}$ faculdades estaduais aos povos indígenas do Paraná, e sua implementação através do Vestibular dos Povos Indígenas a partir do ano de 2002, provocaram intensas reflexões e problematizações acerca da trajetória de acesso e permanência dos indígenas nas instituições de Ensino Superior (IES) públicas.

Inicialmente garantidas três vagas anuais em cada universidade estadual, esse número foi ampliado para seis no ano de 2006, e em 2005 aderiu a esse processo a Universidade Federal do Paraná (UFPR), com a oferta atual de dez vagas por ano. Nesta ocasião, nem as IES públicas do Paraná, nem os indígenas como principais sujeitos desse processo, tinham ciência ou debatiam adequadamente esta ação e a saga que ela iniciaria.

No ano de 2005 foi constituída a Comissão Universidade para os Índios (CUIA Estadual), criada pela Secretaria de Estado de Ciência, Tecnologia e Ensino Superior do Paraná (SETI) com a finalidade de coordenar o Vestibular dos Povos Indígenas. Essa Comissão foi constituída por meio da representação de três membros de cada IES pública do Paraná, e cada IES também passou a organizar sua CUIA local, seguindo formatos distintos.

O ingresso de estudantes indígenas no Ensino Superior se apresentava num contexto caracterizado pela luta reivindicatória dos movimentos e organizações indígenas pela efetiva institucionalização das escolas indígenas no País (nesse 
momento, com significativo respaldo legal e normativo), com a clara intenção de que fosse garantida a Educação Básica bilíngue, específica, diferenciada e intercultural nas terras indígenas, conforme já preconizava a legislação brasileira. O Ensino Superior se apresentava principalmente como estratégia e possibilidade de formação dos professores índios para as escolas indígenas, dada a perspectiva de ampliação da oferta dos anos finais do Ensino Fundamental nas aldeias.

Em decorrência dos processos de escolarização conquistados nas duas últimas décadas pelas sociedades indígenas no Brasil, o Ensino Superior público vem se tornando, muito recentemente, uma das pautas reivindicatórias do movimento indígena em nível nacional. A universidade, como potencial e institucional espaço de produção e socialização do conhecimento acadêmico-científico e da constituição da inteligência nacional, torna-se alvo de direito e lugar a ser alcançado e ocupado pelos povos indígenas como sujeitos históricos e epistêmicos.

Não obstante, a presença dos índios nas universidades públicas oportuniza ainda mais a manifestação das contradições, dos paradoxos e das incoerências que nela residem e a constituem, fundamentalmente, a partir das estratégias de ingresso e de permanência desses sujeitos no ambiente universitário. É nele que passam a se constituir e identificar como estudantes indígenas universitários categoria emblemática, uma vez que se forja a partir de relações sociais marcadas por interações, intercâmbios, resistências, resiliências, ocultamentos, negações e afirmações.

As experiências de educação superior, iniciadas nas IES estaduais do Paraná a partir do ano de 2002 e expressivamente assumidas por outras universidades públicas no País nessa mesma década, revelaram que o conhecimento acadêmico produzido pelos estudantes e pesquisadores indígenas passa a ser estratégico para a afirmação cultural e política dos grupos étnicos aos quais pertencem, assim como para o desenvolvimento das suas comunidades. Por outro lado, essas experiências também revelam a fragilidade das IES públicas no que se refere à garantia de condições acadêmicas e estruturais para viabilização da permanência dos estudantes indígenas. Esse aspecto se apresenta como reflexo da ausência de uma política pública de educação superior para os povos indígenas organicamente definida pelo Governo Federal, considerando a diversidade étnica existente no país, bem como as demandas, realidades e expectativas dos povos indígenas no território brasileiro.

Desta forma, ao se conceber a perspectiva de construção e efetivação de uma política pública de educação superior no Paraná e no Brasil, constata-se que dois elementos são fundamentais, demandando sua compreensão de forma articulada, ou seja, a compreensão sobre quem são os acadêmicos indígenas e os seus percursos na universidade e as trajetórias institucionais trilhadas pelas universidades públicas diante da presença indígena em seu interior. 


\section{Os acadêmicos indígenas e seus percursos na universidade}

O ingresso e a permanência dos acadêmicos indígenas no espaço universitário e urbano (no caso daqueles que passam a residir nas cidades) tornam-se desafiadores para esses sujeitos, que passam a aprender, a vivenciar e a intercambiar diferentes perspectivas, concepções e experiências, provocando e sendo por elas provocados a refletir sobre sua identidade étnica.

As reflexões realizadas acerca desse recente fenômeno possibilitaram a compreensão de que a permanência desses acadêmicos na universidade encontra-se vinculada às suas possibilidades e suas estratégias em manter a dupla pertença que os caracteriza como indígenas e, simultaneamente, como estudantes universitários, mediante a efetivação de seu duplo pertencimento: acadêmico e o étnico-comunitário (AMARAL, 2010).

Contribuem para essas análises as referências, matrizes e conceitos dos campos da educação, da sociologia e da antropologia. Fundamenta essencialmente esse debate a compreensão do conceito relacional de cultura e sociedade, entendendo-se que esta última é composta por múltiplas culturas que mantêm relações umas com as outras, envolvendo conflitos, exclusões, inclusões, trocas, assim como diferenças, desigualdades e ambiguidades. Descarta-se, dessa forma, a ideia de cultura originária ou autóctone, neutra ou isenta de máculas da presença de instituições coloniais, buscando-se retirar as coletividades indígenas de um amplo esquema dos estágios evolutivos da humanidade e passando-se a situá-las na contemporaneidade e em um tempo histórico múltiplo e diferenciado (PACHECO DE OLIVEIRA, 1999).

Essa concepção de cultura orienta-se pela antropologia histórica presente nos estudos de João Pacheco de Oliveira (1999), inspirada na antropologia política e nos estudos das sociedades complexas fundamentados nas reflexões de Eric R. Wolf (FELDMAN-BIANCO; RIBEIRO, 2003), na compreensão sobre os grupos étnicos e as fronteiras étnicas encontrada nas referências de etnicidade de Fredrik Barth (1998), e por fim, pelas reflexões sobre identidade étnica e reconhecimento marcadas pela etnologia indígena de Roberto Cardoso de Oliveira (2006).

Essas reflexões orientam para a superação da idealização da cultura indígena, presente não só nos clássicos da etnologia brasileira, mas também nos livros didáticos, no cinema, na literatura, etc., instigando a ampliar sua compreensão à correspondente abertura analítica para sistemas regionais multissocietários e multilinguísticos, no contraditório contexto capitalista.

Esses fundamentos possibilitam a compreensão do acadêmico indígena não como representante de uma cultura que resiste e é refratária às históricas 
transformações sociais e culturais, mas, ao contrário, como sujeito pertencente a um grupo étnico que já sofreu modificações históricas, atravessadas pelos constantes e intensos contatos com as sociedades não indígenas, principalmente no contexto do desenvolvimento capitalista, mas que evidencia (ou oculta) marcas de sua identidade étnica características do seu grupo de pertença.

Assim, o sujeito acadêmico indígena encontra-se articulado as suas redes de parentesco, as quais orientam a organização sociocultural, econômica e política das sociedades Kaingang e Guarani no Paraná, considerando as especificidades próprias de cada um desses grupos étnicos e da constituição histórica de cada uma das terras indígenas.

Articular as referências conceituais ora apresentadas com a compreensão da existência dos faccionalismos familiares nas terras indígenas (principalmente nos territórios Kaingang) é de suma importância para orientar a caracterização e reflexão sobre o circuito de trabalho indígena que passa a se renovar com a presença desses sujeitos. As manifestações dos sujeitos entrevistados foram fundamentais para se compreender o sentido desse circuito para eles, sendo esta uma provocadora reflexão a ser conduzida pelas IES públicas envolvidas com esta temática

A instituição do Vestibular dos Povos Indígenas do Paraná, desde o ano de 2002, possibilitou o ingresso de vários indígenas das etnias Kaingang e Guarani nas universidades estaduais, bem como de estudantes de diferentes grupos étnicos do Brasil na UFPR, nesta última, desde o ano de 2005. Como a universidade se constitui num espaço de experiência social, tal ingresso oportunizou a esses sujeitos vivências, conhecimentos, relações acadêmicas, sociais e culturais, muitas delas de afirmação ou de ocultamento de sua condição de estudante indígena universitário.

Esses sujeitos, constituídos majoritariamente por jovens indígenas, passam a compor uma nova categoria social, que, na sua essência, é construída cotidianamente por relações de pertencimento e de conflito vivenciadas entre o ambiente da universidade e o ambiente da aldeia de origem.

A pesquisa de tese de doutorado realizada por Amaral (2010) evidenciou alguns dados e fenômenos que marcam as trajetórias percorridas pelos indígenas no Ensino Superior. Nas sete edições do vestibular específico realizadas no período de 2002 a 2008 foram registradas 688 inscrições efetuadas por 488 candidatos indígenas, evidenciando um significativo número de índios que prestam esse concurso por diversas vezes, em diferentes cursos.

Dos 148 candidatos que fizeram sua dupla ou até sétupla inscrição nos vestibulares específicos, 33 (22\%) foram aprovados e efetuaram posteriormente novas tentativas em cursos e IES semelhantes ou distintas. Alguns destes chegaram 
a se matricular nos cursos e IES escolhidos, porém neles não permaneceram. Esse fenômeno se evidencia ainda mais quando se mostram as recorrências na participação dos candidatos inscritos, uma vez que muitos deles se inscrevem nos vestibulares específicos mesmo já estando matriculados e já frequentando outros cursos de graduação.

Os percursos feitos pelos candidatos indígenas ao longo das sete edições dos vestibulares específicos podem revelar fenômenos ainda não percebidos e não compreendidos oficialmente, tais como: a sua expectativa quanto ao evento vestibular dos povos indígenas; o seu nível de compreensão sobre a escolha do curso e IES pretendidos; a relação entre os candidatos e as lideranças indígenas; as fragilidades escolares evidenciadas por meio das avaliações no vestibular; o nível de satisfação e desempenho com o curso frequentado (quando o candidato já é acadêmico), dentre outros (AMARAL, 2010).

A partir dos dados sistematizados na pesquisa, Amaral (2010) destaca que, das 189 vagas disponibilizadas pelas IES estaduais, foram aprovados 173 candidatos indígenas e 139 efetivaram sua matrícula. Do universo de matriculados, 76 permaneciam vinculados às respectivas instituições de ensino, 61 evadiram-se $\mathrm{e}$ dois faleceram. Do universo de 51 acadêmicos indígenas matriculados no período de 2002 a 2004, sete se formaram até o ano de 2007 (13,7\%) e oito se preparavam para sua formatura até o final do ano de 2008 (15,6\%), totalizando 15 indígenas concluintes (29,4\%). Registra-se, não obstante, um significativo índice de evasão de acadêmicos indígenas, totalizando uma média de $44 \%$ dos alunos ingressos pelo vestibular específico. Cumpre destacar que, no tocante à dimensão acadêmica, as IES estaduais que apresentam menor índice de evasão são as mesmas que institucionalizaram processos de acompanhamento dos estudantes indígenas (AMARAL, 2010).

Verifica-se também que o curso que registra o maior número de estudantes evadidos é o de Pedagogia, o que instiga a problematização sobre aspectos como a sua organização curricular nas diferentes IES, as expectativas dos acadêmicos indígenas evadidos acerca desse curso e as possíveis influências na oferta dos cursos de Magistério Indígena pela Secretaria de Estado da Educação (SEED), nesse contexto, dentre outras reflexões.

Constata-se que, dos 76 estudantes indígenas matriculados no ano de 2008, 35 pertencem a cursos de licenciatura (área da educação), representando $46 \%$ do total de matrículas ativas no referido período. Dos 76 matriculados, 22 estão vinculados a cursos da área da saúde, representando $29 \%$ do universo. Os demais 19 estudantes indígenas matriculados ( $25 \%$ do total) estão vinculados a cursos das áreas das ciências sociais aplicadas (Direito, Administração, Serviço Social e Secretariado Executivo), de Comunicação Social e Agronomia. 
A partir dos relatos dos acadêmicos indígenas entrevistados por Amaral (2010), pôde-se caracterizar e analisar o seu pertencimento acadêmico considerando-se aspectos como a referência da escolarização básica para a sua formação acadêmica, as precárias condições materiais e financeiras para garantir sua permanência na universidade e no meio urbano, os limites e as iniciativas de acompanhamento institucional pelas IES, os preconceitos e as experiências de interculturalidade vivenciados no ambiente acadêmico e o sentimento de estrangeirismo na univer-cidade.

Esses elementos demandam uma profunda reflexão sobre o desenho e o lugar institucional da política pública de Ensino Superior para os povos indígenas, entendendo-se que o ineditismo revelado pela iniciativa e pela experiência paranaense nessa última década (com todos os seus desafios, limites e potencialidades), pode contribuir de forma significativa para os contornos institucionais desta ação enquanto política pública de educação no Brasil.

\section{As trajetórias institucionais trilhadas pelas universidades públicas diante da presença indígena}

A presença de estudantes indígenas nas universidades é um fenômeno historicamente recente no Brasil, encontrado principalmente da última década, constituindo-se como resultado das lutas e movimentos de lideranças e professores indígenas por garantir o acesso à educação básica e superior às populações indígenas do País. Apesar dos avanços na legislação brasileira para a Educação Escolar Indígena, muito recentemente foi promulgada a Lei n. ${ }^{\circ}$ 12.416/2011, que altera a Lei n. ${ }^{\circ}$ 9394/1996, de Diretrizes e Bases da Educação Nacional (BRASIL, 1996), e dispõe sobre a oferta de educação superior a povos indígenas no Brasil contemplando no seu texto:

No que se refere à educação superior, sem prejuízo de outras ações, o atendimento aos povos indígenas efetivar-se-á, nas universidades públicas e privadas, mediante a oferta de ensino e de assistência estudantil, assim como de estímulo à pesquisa e desenvolvimento de programas especiais. (BRASIL, 2011, Art. $\left.1^{\circ}, \S 3^{\circ}\right)$.

Essa disposição legal ainda não se apresenta regulamentada e tampouco conta com diretrizes nacionais que a orientem. Nesse caso, dada a ausência de uma política pública nacional de educação superior para os povos indígenas, a centralidade das reflexões sobre essa temática sugere a compreensão e análise das experiências em curso, com destaque para a experiência paranaense.

A política pública de Ensino Superior para os povos indígenas no Paraná se caracteriza pela articulação de vários elementos institucionais, como: a oferta 
sistêmica de vagas suplementares nas universidades públicas do Paraná garantida por lei (incluindo-se a UFPR, por meio de convênio específico); o repasse mensal de bolsa-auxílio aos estudantes indígenas matriculados; a estruturação de espaços institucionais de coordenação, acompanhamento e monitoramento desta política por meio do órgão gestor do ensino superior público no Paraná - a SETI, através da institucionalização da CUIA; o desenho institucional voltado ao acompanhamento pedagógico dos acadêmicos indígenas por meio da constituição de CUIAs locais em cada uma das IES públicas; e por fim, a institucionalização e realização anual do Vestibular dos Povos Indígenas, que é um processo seletivo específico aos povos indígenas pertencentes ao Paraná e a outros grupos étnicos do país (estes últimos, para concorrer às vagas ofertadas pela UFPR).

Desde a instituição do Vestibular dos Povos Indígenas do Paraná, cada IES estadual passou a desenvolver ações institucionais voltadas à permanência dos estudantes indígenas no Ensino Superior, embora nem todas estejam regulamentadas internamente por essas Instituições e pela SETI e articuladas em nível estadual, além de serem insuficientes para a constituição de uma política pública de Estado.

Reflexo da orientação original da SETI ao instituir o vestibular específico, a política de acompanhamento dos estudantes indígenas não foi assumida como gestão prioritária pela Secretaria de Estado da Educação, cabendo às IES estaduais a organização e o desenvolvimento de ações para atendimento às necessidades acadêmicas e sociais dos estudantes indígenas, conforme a disponibilidade, capacidade e orientação de cada uma das instituições de ensino (AMARAL, 2010).

Cumpre destacar o papel e a importância institucional da CUIA em constituir-se num espaço de articulação e socialização das experiências de acompanhamento acadêmico realizadas pelas IES envolvidas; porém se observa que, desde a sua criação até o presente momento, o foco de atenção prioritária desta Comissão, assim como da SETI, encontra-se na organização dos vestibulares específicos (PAULINO, 2008). Só muito recentemente a CUIA passou a voltar suas atenções à questão da permanência dos acadêmicos indígenas, pautadas pela realização das três edições do Encontro Estadual de Ensino Superior do Paraná (no ano de 2008, organizado pela UEL; no ano de 2009, organizado pela UEM; no ano de 2011, pela UFPR) e na constituição do Grupo de Trabalho Permanente de Educação Superior Indígena (GTPEEI), criado no ano de 2012 e vinculado a essa Comissão.

Entende-se que um dos elementos capazes de cimentar o pertencimento acadêmico dos estudantes indígenas em seu processo formativo é a garantia das condições de permanência, entre elas, o acompanhamento acadêmico pelas IES públicas. Amaral (2010) evidencia uma caracterização e análise do que vem se 
denominando políticas de permanência dos estudantes indígenas nessas instituições, destacando seis elementos fundamentais: 1) a institucionalização das ações de acompanhamento dos estudantes indígenas; 2) a disponibilidade institucional das IES; 3) a disponibilidade de docentes e condições de trabalho; 4) a relação com a pesquisa e extensão; 5) o acompanhamento pedagógico direto aos acadêmicos indígenas; e 6) as condições de residência para os acadêmicos indígenas. Essa análise é também referenciada por Paulino (2008, p. 102) quando afirma:

[...] as diferentes condições de permanência dos indígenas oferecidas pelas universidades merecem atenção. Cabe deixar claro: a existência de um único "Vestibular dos Povos Indígenas do Paraná" não corresponde ao oferecimento dos mesmos recursos para a permanência dos ingressos em cada instituição.

Essa compreensão também é problematizada por Capelo e Tommasino (2004, p. 25) ao constatarem as diferenças institucionais existentes entre as IES nas condições de permanência aos acadêmicos indígenas, evidenciando a inexistência, para isso, de uma "política comum entre as universidades paranaenses".

Concordando com essa análise, Amaral (2010) compreende que a política interinstitucional estadual de permanência dos estudantes indígenas nas IES estaduais se caracteriza pela concessão da bolsa-auxílio repassada mensalmente pela SETI e pela institucionalização da CUIA estadual, ações que estão regulamentadas pela SETI. As demais ações e providências passam a ser de responsabilidade de cada uma das IES, uma vez que possuem, em tese, autonomia para tal.

Outrossim, segundo o autor, como avanço pode-se destacar o processo de institucionalização da presença indígena em algumas IES do Paraná por meio da apreciação e deliberação dos seus órgãos colegiados superiores, com aprovação dos programas de ensino, criação das comissões de acompanhamento e da definição de carga horária dos docentes para desenvolverem esta ação. Essas referências são importantes e representam avanços para a história da educação escolar indígena e da oferta do ensino superior aos povos indígenas no País e no Paraná, apesar de não serem comuns a todas as Instituições.

Como a universidade se constitui num espaço formativo potencial, entende-se que o papel fundamental da CUIA Estadual e das comissões em cada uma das IES consiste na criação de condições efetivas para garantir uma formação acadêmica intercultural e de qualidade aos acadêmicos indígenas. Além de articular as condições objetivas que venham a garantir a permanência dos estudantes indígenas, seu papel é propiciar a mediação entre os conhecimentos científicos e acadêmicos e os conhecimentos tradicionais existentes nas comunidades, envolvendo os diferentes setores e coordenações de cursos nesta discussão. 
Esse desafio passa a ser compartilhado com diversas IES públicas do País, as quais passam também a acolher estudantes indígenas. Ao refletir sobre a experiência de implantação dos cursos de licenciatura intercultural e de acompanhamento dos estudantes indígenas, Antônio Brand (2007, p. 126-127) manifesta sua preocupação com as sedimentadas trilhas desenvolvidas no ambiente acadêmico, nem sempre abertas às lógicas indígenas:

No entanto, o grande impasse que, como professor, percebo nas nossas reuniões e nos trabalhos de formulação do projeto das licenciaturas, em conjunto com os participantes indígenas, diz respeito às dificuldades não dos índios, mas das nossas universidades. Eu creio que nós, os professores e as universidades, temos uma imensa dificuldade de sair de nossas "trilhas" de conhecimento já muito bem sedimentadas para verificarmos, na prática e no dia-a-dia, como é que isso está se dando junto a outros povos, que experiências eles estão conseguindo acumular e como poderíamos trocar a partir das experiências de produção de conhecimento desses povos. O risco é, mesmo escrevendo projetos inovadores, bonitos, continuarmos na realidade a impor as "nossas" velhas práticas pedagógicas e certezas acumuladas, mesmo sabendo que as nossas universidades nem sempre atingem os melhores resultados. [...] Então, quero destacar este desafio, para evitar que projetos bem elaborados acabem, em sua execução, impondo aos índios os "nossos modos de pensar" e de construir conhecimentos.

Essas lógicas se manifestam nas formas de organização curricular dos cursos e nas relações sociais e pedagógicas estabelecidas entre professores e estudantes (indígenas e não indígenas) no cotidiano do processo formativo. Relatando e refletindo sobre os dilemas vivenciados no seu processo de formação no Ensino Superior, Francisca Novantino P. de Ângelo Pareci (2007, p. 81-82) convida a revisitar as propostas curriculares em vigência:

Vamos pensar agora em uma proposta para a questão universitária; não é possível falar de Ensino Superior com a universidade do jeito que está por aí, sem uma reforma curricular, sem uma reforma da sua proposta ideológica, filosófica e pedagógica. Nossos professores indígenas mostram-se preocupados com a solução a ser encontrada, exatamente porque a universidade ora pode incluir, ora pode excluir e, nesse sentido, ela é capaz também de deixar claro para o índio que está se formando - e que depende muito de quem o forma - que ele deve ficar fora da aldeia e discriminar o seu povo.

Nessa lógica, entende-se que um dos elementos desse processo de institucionalização, ainda que não evidenciado pelos entrevistados, refere-se à flexibilidade curricular prevista explícita e oficialmente na UEM e na UFPR, sendo mais sutil na UEL (PAULINO, 2008). Tal flexibilização se reflete na ampliação dos prazos de jubilamento no curso, nas condições especiais de trancamento de matrícula no caso de baixo rendimento e nas facilidades nos processos de 
transferência de curso ou de IES, assegurando condições diferenciadas, quer pela garantia de reorganização do tempo de formação acadêmica, quer pela mobilidade entre cursos e IES devido à frequente falta de informação dos indígenas em relação ao perfil de cada carreira.

Fundamentalmente, é pressuposto para análise das políticas e experiências de acolhimento e de garantia de permanência aos estudantes indígenas desenvolvidas pelas IES públicas do Paraná conhecer as especificidades de cada Instituição e as relações hierárquicas e de poder nelas existentes e identificar em qual lugar institucional situam-se as CUIAs locais. Esse processo de institucionalização é problematizado por Paulino (2008, p. 102, grifo do autor), que apresenta aspectos importantes para essa análise, ao afirmar:

Em relação à institucionalização de políticas de permanência dentro de cada universidade, percebe-se que esse processo também se dá de maneira diferente em cada uma delas por estar sujeito: 1. à estrutura burocrática de cada instituição, em que se apresentam níveis diferentes de dificuldade para encontrar (ou abriir) possíveis brechas para a implementação de tais políticas; 2. ao engajamento (ou à resistência) de pessoas - a mudança de um quadro às vezes muda todo o contexto para melhor ou para pior. Em relação a isso, percebemos que certas iniciativas só existem graças ao trabalho árduo de alguns professores, sem nenhum ou quase nenhum apoio institucional. Desta forma, quando professores como estes não existem ou estão temporariamente ausentes, o que já é difícil se torna praticamente impossível.

Cabe observar que, assim como os estudantes são responsabilizados individualmente pelo que deveria ser de responsabilidade institucional, a inexistência de instâncias formalizadas e a falta de regulamentação apropriada para a concretização de uma inclusão efetiva são duas faces de um só fenômeno (AMARAL, 2010).

Ao referenciar sua experiência de participação nas comissões de organização das edições do Vestibular dos Povos Indígenas (período de 2001 a 2004), Amaral (2010) identifica e problematiza como um dos limites mais significativos presentes na CUIA a questão da personificação da política de acompanhamento acadêmico nos docentes ou técnicos das IES. Afirma o autor:

Esse fenômeno, presente desde a institucionalização dos vestibulares específicos, passa a marcar a fragilidade e, muitas vezes, a descontinuidade das ações desenvolvidas, assim como a condição de permanência dos estudantes indígenas nos cursos escolhidos e nas Instituições de Ensino, uma vez que são mediadas e vinculadas exclusivamente a determinados docentes. Esse é um dos reflexos da ausência de uma política pública consolidada de ensino superior aos povos indígenas que se institua de forma sistêmica e contínua no interior das IES e na rede pública responsável por este nível de ensino em todo o país. (AMARAL, 2010, p. 322). 
Ao refletir sobre a ausência de uma política pública ampla e específica de fomento à pesquisa sobre as questões indígenas no Brasil, a qual pudesse envolver os próprios acadêmicos indígenas (por meio de linhas de iniciação científica), Silva (2007, p. 135) evidencia "o fato de nós termos que ter coragem de assumir que não existem políticas oficiais para os povos indígenas nas nossas instituições. Certamente existem pesquisadores, mas não existe uma política do CNPq."

Essa questão revela a fragilidade da política pública de Ensino Superior voltada aos povos indígenas no Brasil, sendo o fenômeno também evidenciado em outras universidades públicas que acolhem estudantes indígenas (LIMA; BARROSO-HOFFMANN, 2007). No Paraná, essa referida personificação fica ainda mais complexa ao se considerar a alta rotatividade dos membros das CUIAs locais, a qual prejudica e compromete a continuidade das ações desenvolvidas.

A situação apresentada pode ser melhor explicitada quando se observam os índices de rotatividade do número de docentes envolvidos nos Vestibulares dos Povos Indígenas e na CUIA Estadual no período de 2002 a 2007. Segundo Amaral (2010), dos 55 docentes formalmente envolvidos e nomeados para a realização de seis vestibulares específicos (2002 a 2007) e, consequentemente, para a composição da CUIA Estadual (2005 a 2007), cerca de 56\% participaram desta ação apenas por um ano, sendo essa função transferida a outros docentes das IES a que estavam vinculados (incluídos, neste caso, os docentes das estaduais e da UFPR). Apenas oito docentes participaram de três vestibulares específicos consecutivos ( $50 \%$ dos vestibulares realizados no período citado), representando $14,5 \%$ do total de professores envolvidos nesta ação. Apenas uma professora do total de docentes participou consecutivamente da série histórica de todos os vestibulares específicos do Paraná.

Somando-se a esse fenômeno, além da reduzida adesão de docentes interessados neste trabalho, evidencia-se a insuficiente disponibilidade de tempo dos membros da CUIA local para acompanhamento dos estudantes indígenas nas IES, uma vez que é reduzida a carga horária destinada para tal e em duas das IES pesquisadas simplesmente não existe essa carga horária disponível (AMARAL, 2010). Ademais, segundo o autor, a disponibilidade de carga horária não significa sua suficiência, sua efetividade ou mesmo o interesse e o compromisso dos docentes em acompanhar os estudantes.

Constata-se também que os estudantes indígenas que residem nas cidades sedes das IES ou em terras indígena próximas a elas acabam tendo maior contato e acompanhamento dos docentes. Os que precisam se deslocar diariamente de seu município para uma universidade ou faculdade que não conta com docentes disponíveis para esta ação acabam prejudicados (AMARAL, 2010).

O envolvimento direto e pessoal de alguns docentes membros das CUIAs revelou a constituição de um novo pacto político de compromisso entre eles e 
as comunidades indígenas do Paraná, aí incluídos os contatos e as contribuições anteriores desses pesquisadores em suas ações junto a esses povos; porém é preciso estabelecer um novo pacto interinstitucional pela constituição de uma política pública de permanência dos estudantes indígenas, mais integrada e efetiva no Paraná.

Importante ressaltar que a UEM e a UEL passam a se destacar junto às demais IES estaduais pela institucionalização de ações de acompanhamento dos estudantes indígenas, algumas delas articuladas à pesquisa e à extensão, com garantia de determinadas condições materiais e pedagógicas importantes para a permanência dos alunos (CAPELO; AMARAL, 2004; CAPELO; TOMMASINO, 2004; RODRIGUES; WAWZYNIAK, 2006; NOVAK, 2007, 2008; PAULINO, 2008; MONTEIRO; CARVALHO, 2008). Também a UFPR passa a ter um destaque nas ações de acompanhamento pedagógico e principalmente nas de envolvimento dos acadêmicos indígenas em ações voltadas à pesquisa e à extensão.

A UEL foi a primeira a aplicar, já no ano de 2003, um programa de ensino específico para acompanhamento dos estudantes indígenas ingressos por meio dos vestibulares específicos, denominado "Programa de Formação Intercultural", desenvolvendo importantes ações para constituir uma referência institucional às demais IES. No ano de 2009 regulamentou o acesso e a permanência de estudantes indígenas ingressos por reserva de vagas, nos cursos de graduação (Resolução CEPE/UEL N. ${ }^{\circ}$ 04/2009). Sua geográfica proximidade das terras indígenas e a existência da sede da Administração Regional da FUNAI na cidade de Londrina também possibilitaram algumas condições de segurança e permanência aos estudantes (PAULINO, 2008).

Por sua vez, a UEM passou a constituir uma política de acompanhamento dos acadêmicos indígenas de forma mais sistemática, sólida e estruturada, conforme se pode observar no relato de uma estudante Guarani do curso de Pedagogia nessa universidade, a partir de pesquisa realizada por Amaral (2010, p. 327-328):

Daí é diferente aqui que eu já vi [na UEM]. Daí, minha mãe veio aqui conheceu a J. e ela falou que é muito diferente, é muito bom e para estudar a gente tem espaço e além do mais, tem o pessoal da universidade. O próprio professor dá assistência na parte de ajudar mesmo, os alunos na disciplina; uma monitoria específica para os indígenas. [...] A CUIA tem bastante influência também. [...] Ajuda para fazer um trabalho nas aldeias indígenas, já tem um conhecimento, já sabe como é, então... [...] Contribui, porque eu fico pensando que eu estou na reserva indígena [morar com outros estudantes indígenas no Centro Cultural]. As crianças têm um espaço para brincar. [...] Então, aqui, é melhor para estudar, tem um que é bem quietinho, a criançada fica brincando à vontade. 
Avalia-se que esse destaque se justifica pelo acesso e permanência dos estudantes indígenas no Laboratório de Arqueologia, Etnologia, e Etno-História - LAEE (popularmente chamado de "Tulha", por ser uma antiga casa de madeira dentro da Universidade) e pelo fato de a UEM contar com uma equipe que apresenta reduzida rotatividade de docentes e pesquisadores, haja vista seu envolvimento em outros projetos de pesquisa e extensão voltados aos povos indígenas do Paraná (PAULINO, 2008; AMARAL, 2010). Esse destaque coloca a UEM como uma instituição buscada e desejada por vários dos candidatos indígenas, haja vista a estrutura acompanhamento e de moradia - esta implantada em parceria com uma organização não governamental - bem como a inserção nas comunidades indígenas por meio das ações e da equipe do referido Laboratório.

Mesmo com a estrutura garantida com destaque pela UEM e pela UEL e, de forma incipiente, pelas demais IES estaduais, os limites financeiros são constantemente evidenciados pelos estudantes indígenas entrevistados, reflexo das precárias condições econômicas vivenciadas nas comunidades indígenas, bem como do reduzido valor da bolsa-auxílioํ. Essa manifestação está também associada à limitada capacidade de resposta institucional das universidades e da FUNAI, a qual impõe a essas instituições e aos próprios acadêmicos indígenas a busca de alternativas para sobrevivência sua e de suas famílias.

Merecem destaque os arranjos e as articulações interinstitucionais constituídos principalmente para garantir o acolhimento dos estudantes indígenas ingressos pela via dos primeiros vestibulares específicos, sob a forma de campanhas e parcerias com organizações não governamentais, por meio de doações de professores e de instituições apoiadoras, constatáveis ainda hoje em algumas IES, segundo relato de pedagoga Kaingang formada pela UEPG e entrevistada por Amaral (2010, p. 329-330):

No primeiro ano que a gente foi para Ponta Grossa, a gente não tinha previsão de bolsas. A gente ficou, mais ou menos, um ano sem receber bolsa, só com ajuda das igrejas, da pastoral da saúde, da própria comunidade, da FUNAI a gente teve um pouquinho, mas... [...] Com as conversas que a gente tem, acaba conhecendo pessoas que querem ajudar a comunidade indígena e eu acabei conhecendo uma pessoa da Prefeitura de Ponta Grossa e essa pessoa me ajudou bastante na questão do transporte, eu recebia passes. [...]

\footnotetext{
${ }^{1}$ No período de 2002 a 2003, o valor da bolsa-auxílio aos estudantes indígenas universitários correspondia a R\$ 250,00/mês, não havendo regulamentação oficial para esse repasse. Somente com a Resolução $\mathrm{N}^{\circ}$. 014/2004 da SETI é que ficou regulamentado e fixado o valor de R \$270,00 para a referida bolsa-auxílio, sendo posteriormente equiparada ao valor do salário mínimo pela Resolução Nº 029/2006 da SETI, elevando-se para o valor de R \$350,00 no mesmo ano. Somente com a Lei Estadual n $n^{\circ}$ 15.759/2007 e pela Resolução SETI n. 015/2008, que institui o Programa Bolsa Auxílio para Estudantes Indígenas, que há um acréscimo no valor da bolsa passando à $\mathrm{R} \$ 400,00$ garantindo-se o acréscimo de $50 \%$ neste valor para os acadêmicos que comprovem a guarda de filhos, independentemente do número de dependentes. A Resolução SETI Nº 179/2010 elevou o valor da bolsa-auxílio em $\mathrm{R} \$$ 633,00/mês, mantendo o acréscimo pela guarda dos filhos.
} 
No primeiro ano que a gente esteve lá, a gente passou muita dificuldade e ela esteve nos ajudando, tirava do próprio bolso dela para ajudar fazer compras, a gente tinha dois filhos; ela me ajudou bastante, até o final do curso. [...] Ela sempre falava para nós que qualquer coisa que a gente precisasse, ela estava à disposição. A única pessoa com quem a gente contava era com ela.

A falta de uma política pública interinstitucional efetiva de apoio à permanência dos acadêmicos os coloca numa posição de mendicantes de ações, serviços e benefícios que lhes deveriam ser de direito. A negação do direito de efetiva permanência no ensino superior público possibilitou, paradoxalmente, a afirmação de sua condição autônoma de se organizarem individualmente ou em grupos e buscarem alternativas e respostas para resolver os problemas financeiros vivenciados diante da inoperância e da histórica tutela institucional, fundamentalmente da FUNAI.

A constatação das alternativas buscadas pelos estudantes indígenas apresenta-se articulada às permanentes reivindicações acerca do papel institucional do Governo do Estado e das universidades de prover condições adequadas de moradia estudantil, fornecer materiais e elevar o valor da bolsa-auxílio, como se observou nos relatos anteriores. As fragilidades estruturais constatadas passam a despertar também possibilidades de organização dos estudantes indígenas, como explicitado por um dos acadêmicos entrevistados (AMARAL, 2010, p. 330-331):

No caso de algumas pessoas, a G., a L. que, às vezes, andam tudo para lá, outro para cá, assim, que passam muita dificuldade. Vão à Funai, pedem cesta básica. E nós, o último dinheiro do mês que a gente tinha guardado era vinte reais, que a gente fez a compra e guardou vinte reais para inteirar o dinheiro do gás e para mais alguma coisa que faltava. Aí, ontem, nós gastamos esse dinheiro para chegar até na outra bolsa. Fazia uns vinte dias que a gente tinha guardado esse dinheiro para chegar, então... Eu falei para eles se a gente se organizar, a gente leva. Agora, se chegar, pegar e ficar tudo desorganizado e esperando, aí, cada um cuidando de si, à sua maneira, às vežes, não chega a lugar nenhum. Então, se a gente se organizar, a gente chega em algum lugar, sim. Então, a gente não passa dificuldade em casa, por causa disso aí. A gente é bem organizado. [...] A gente teve que se virar com as próprias pernas, então, isso para nós foi ruim. E daí, o que é que eu fiz? Cada um se virou com o que podia, cada um correu em algum lugar, arranjou colchão. Às vezes, quem arranjava colchão não tinha coberta, dormia sem coberta. Eu já tinha minha roupa, né? Eu peguei, forrei no chão e me cobri com o meu jaleco da Medicina que eu tinha guardado. Pelo menos, me serviu pra alguma coisa. Mas então, aí, os mesmos problemas que um enfrenta, o outro enfrenta. Então, aí, o que a gente vê com os colegas, lá? Os colegas da casa, a gente está unido. Eu falo se tiver algum problema, a gente resolve. Pelo menos, se tiver algum problema entre nós, senta, vamos discutir. Mas a discussão nossa vai ser para melhorar as coisas, para ninguém passar 
apuro. Porque eu falo para eles que eu sei o que já passei aqui, então, eu acho que deve saber levar as coisas para poder chegar em algum lugar. Tem que entrar em consenso, porque se um concorda e o outro discorda, não dá certo. Então, é assim que a gente se mantém unido lá ainda. (Estudante Kaingang do curso de Medicina no período dessa entrevista, atualmente matriculado no curso de Artes na UEL, grifo nosso).

Cumpre ressaltar a necessária problematização e avaliação, pelas IES estaduais, do seu papel como gestores da concessão das bolsas-auxílio para os estudantes indígenas, sendo que, em algumas delas, a política de acompanhamento desses acadêmicos se resume a esse monitoramento. Paulino (2008) destaca em seu trabalho o histórico avanço que representou a bolsa-auxílio, mas questiona a lógica presente na concessão e monitoração das referidas bolsas, principalmente do "contrato" estabelecido entre a SETI e as IES e os estudantes indígenas beneficiados (previsto na Lei Estadual N. $\left.{ }^{0} 1.575 / 2007\right)$. Também critica os conceitos e critérios que definem este benefício, principalmente a frequência mínima às aulas e o desempenho escolar suficiente, este último, no caso dos acadêmicos indígenas da UFPR.

Esse autor alerta sobre os cuidados necessários para adequar os referidos critérios às características socioculturais e realidades vivenciadas pelos estudantes indígenas, principalmente pelas dificuldades de deslocamento diário da terra indígena para a universidade, pela condição paterna ou materna de significativo número de estudantes, entre outros aspectos também reais e comuns a estudantes não indígenas.

As dificuldades econômicas decorrentes da insuficiência da bolsa-auxílio reforçam a dupla ou mesmo tripla jornada por eles assumida - o estudo, o trabalho para buscar a sobrevivência própria e da família e os trabalhos domiciliares no cuidado da casa e dos filhos. Ademais, há também o desgaste físico e mental para corresponder duplamente às exigências sociais, culturais e acadêmicas como estudantes de um curso integral e como estudantes indígenas. Geralmente o estudante indígena é depositário das expectativas de sua família e/ou de sua comunidade (em suas relações faccionais) no ambiente acadêmico, assim como, na maioria dos casos, é responsável pela manutenção dos filhos e por sua vinculação com o universo cultural de seu grupo étnico-comunitário.

Entende-se que, mais do que o insuficiente valor da bolsa-auxílio, é necessário um estudo mais profundo para identificar quais seriam os entraves ao envolvimento dos estudantes indígenas em ações acadêmicas que não sejam a frequência às aulas. Esse aprofundamento pode contribuir para problematizar e mesmo corroborar algumas das hipóteses apresentadas por Rodrigues e Wawzyniak (2006, p. 29) sobre a ausência dos estudantes indígenas nas monitorias organizadas pelos docentes membros das CUIAs locais: 
Como principal dificuldade para a realização das monitorias de acompanhamento, tanto na UEL quanto na UEM, poderíamos indicar a ausência dos estudantes aos encontros. Razões para explicar isso? No momento apenas podemos aventar algumas hipóteses. Uma delas talvez seja a tentativa do estudante indígena em evitar o reconhecimento público das dificuldades oriundas do ensino médio e fundamental. Uma outra, explicitada pelos próprios estudantes indígenas, se refere a ausência de uma rotina de estudos. Segundo eles, a leitura e o estudo sistemático não fazem parte de seu cotidiano, de sua cultura. Afirmam que estudam para fazer as "provas" e que estudam pouco porque a universidade, muitas vezes, exige pouco. Outra ainda, também recorrentemente explicitada pelos próprios estudantes indígenas refere-se a inexpressiva validade que eles atribuem aos conteúdos ensinados na universidade.

É preciso cuidar para que as hipóteses levantadas pelos autores, dada a sua importância, não venham a implicar a exclusiva e genérica culpabilização do estudante indígena por sua ausência nas atividades desenvolvidas, seja pela ocultação de seus limites escolares, seja por ele não ter, culturalmente, uma rotina de estudos, seja ainda pela pouca significação por ele atribuída aos conteúdos acadêmicos; contudo é necessário explicitar as condições financeiras, pedagógicas, psicológicas e institucionais em que essas manifestações se apresentam, para superar possíveis generalizações e estereótipos.

Ao refletir sobre as frágeis condições institucionais oferecidas aos estudantes indígenas pelas IES estaduais e os riscos de estigmatização desses sujeitos, Capelo e Tommasino (2004, p. 25) afirmam:

[...] os estudantes indígenas sofrem as mesmas injunções que os não índios, no entanto, devido às características culturais e trajetórias escolares (que geralmente resultam de um ensino médio precário) exigem acompanhamento mais direto, a fim de que a inclusão precária não resulte em exclusão absoluta. Tal acompanhamento visa reduzir as consequências do fracasso escolar, especialmente para que não seja utilizado como justificativa para estigmatizar ainda mais os índios, reforçando a ordem vigente que se mantém, embora ressignificada em muitos aspectos, praticamente inalterada ao longo da história de contato.

Necessário também se faz considerar que as exigências de um curso integral, junto com a precária condição financeira em que eles vivem na cidade, não contribuem e muitas vezes impedem a sua participação em outras ações acadêmicas ou culturais na universidade que são imprescindíveis para a formação intercultural deles e dos estudantes não indígenas, além de inviabilizarem a aproximação institucional entre universidade e as comunidades indígenas.

As dificuldades dos estudantes índios em desenvolver projetos de pesquisa e extensão voltados às necessidades das comunidades indígenas 
por vezes impedem a construção e o fortalecimento de seu pertencimento e de sua vinculação acadêmico-cultural com suas comunidades de origem e a manutenção dos laços com os grupos parentais de pertença. Entende-se que esta ação é importante não apenas para a formação acadêmica do estudante indígena universitário, mas também para a afirmação de seu pertencimento étnico-comunitário (AMARAL, 2010), principalmente a sua família e às relações faccionais e parentais a que pertence na comunidade. Amaral (2010, p. 236-237) explicita essa importância no relato de pedagoga Kaingang formada pela UEPG:

Pode contribuir bastante porque, além dos indígenas estarem na Universidade, eu acho que eles têm que partir pelos alunos ali que estão ali dentro para estar alcançando esse conhecimento, também, através das comunidades dos indígenas, as lideranças. [...] Lá no Apucaraninha a gente tem os projetos da universidade que estão sendo executados, têm alunos que participam e que vão toda semana. Então, a gente vê interesse dos não indígenas ali, alguns acadêmicos, junto com os professores que estão tentando fazer alguma coisa para comunidade.

A presença institucional de professores e de estudantes não indígenas atuando nas terras indígenas pode também possibilitar o conhecimento intercultural na formação dos profissionais das diferentes áreas. Observa-se que a limitada contribuição que as universidades oferecem às comunidades também passa a ser assumida e justificada pelos próprios estudantes indígenas. Revela-se nos relatos dos entrevistados que o desenvolvimento de projetos de extensão e pesquisa pelos estudantes indígenas seria uma estratégia para integrar suas ações acadêmicas com as necessidades das comunidades; contudo é importante questionar e problematizar a atuação dos projetos de extensão e pesquisa que envolvam os estudantes indígenas em suas comunidades de origem, considerando as relações de poder e de faccionalidades existentes nessas localidades nas quais os acadêmicos índios e suas famílias estão envolvidos.

A determinação institucional ou moral da atuação dos estudantes indígenas em suas comunidades como retorno dos conhecimentos acadêmicos aprendidos pode significar para eles um reconhecimento e um benefício, mas também pode constituir-se em um transtorno, haja vista os possíveis conflitos existentes nas aldeias a que pertencem, principalmente entre eles, os respectivos grupo faccionais ou parentais e as lideranças indígenas no comando político e suas terras. Essa situação se evidencia no relato de um dos entrevistados ao se referir às dificuldades das lideranças de sua comunidade em aceitar sua posição como estudante universitário e futuro profissional e a contribuição que poderia apresentar à comunidade (AMARAL, 2010, p. 338):

Tem gente que pode não querer porque tem pessoas lá que moram na cidade, que é índio, mora na cidade e, às vezes, não admite que a gente chegue lá e 
tome a vaga deles. E pessoas, assim, que, às vezes, não tem um curso, assim, como o meu que é um curso de faculdade, que é um conhecimento muito grande, que a gente tem em comparação a eles, eles não admitem a gente chegar e impor um conhecimento que, às vezes, não está na verdade, compatível com o conhecimento que eles estão aplicando lá. Então, isso, na verdade, vai gerar um conflito entre a escola, mas a gente vai ter que chegar num consenso nisso aí. (Estudante Kaingang do curso de Medicina no período dessa entrevista, atualmente matriculado no curso de Artes na UEL).

Revela-se, dessa forma, a importância de compreender e considerar as relações locais de poder nas aldeias, as quais nem sempre se explicitam no processo de inscrição dos candidatos indígenas ao vestibular específico, mas na relação cotidiana entre as famílias dos acadêmicos, na relação de ensino, pesquisa e extensão com as universidades e os docentes da CUIA, assim como nas perspectivas de trabalho e emprego após a conclusão dos cursos.

Cabe ressaltar os cuidados que devem ter os gestores da estrutura administrativa e acadêmica das universidades, representados pelos membros da CUIA, ao deliberarem sobre a relação de retorno dos conhecimentos e práticas entre os estudantes indígenas e suas comunidades. Paulino (2008) critica a forma como a Portaria N. ${ }^{\circ}$ 63/2007 estabelece normas acerca da oferta do Ensino Superior aos povos indígenas no Brasil, principalmente no tocante à concessão das bolsas-auxílio. $\mathrm{O}$ autor define este retorno

Como uma espécie de "pagamento" pelo auxílio, o estudante torna-se, portanto, obrigado a desenvolver "proposta de trabalho" em alguma comunidade. Não nos parece a melhor forma de incentivo ao atendimento das demandas indígenas, embora compreendamos que este pré-requisito possa ser uma estratégia para evitar a desconexão dos acadêmicos com os povos. (PAULINO, 2008, p. 92, grifo do autor).

Outro aspecto identificado nos relatos dos estudantes indígenas entrevistados que limita a identidade e o desempenho acadêmico refere-se à frustração de alguns estudantes indígenas em não poder participar de eventos científicos locais, estaduais, nacionais e internacionais que complementariam a sua formação acadêmica, devido à falta de recursos financeiros (AMARAL, 2010, p. 339):

E eu tenho também congressos. E eu não fiz nenhum congresso porque não sobra dinheiro. Por isso é que eu falo que ela [a bolsa] não é suficiente. Ela dá pra gente se manter apertado, né, para você pagar o básico. Agora, uma coisa que é por fora, mas que é necessário, no caso, um congresso, simpósio, aí não sobra. Aí, nesses casos, ela é insuficiente. [...] E você, às vezes, não pode fazer, não pode participar de um congresso porque, às vezes, não tem 10 reais no bolso. Tem congressos que eu perdi porque não tinha 10 reais no bolso. Então, é ruim, é muito chato. (Estudante Guarani do curso de Medicina na UEL no período dessa entrevista, atualmente matriculada no curso de Medicina na UEM). 
O relato evidencia que a construção da identidade do estudante indígena universitário passa pela definição de uma política pública de educação superior que subsidie financeiramente sua permanência e garanta o acompanhamento das universidades. A falta de efetivação dessa política pode acarretar a assunção e afirmação da individual e insólita responsabilidade pela trajetória acadêmica do estudante indígena, dada a limitada capacidade de cada um para sobreviver no ambiente urbano e universitário, conforme relato apresentado (AMARAL, 2010, p. 339-340):

Quando eu estava naquele apuro mesmo, sem dinheiro, sem condições, porque eu dormi várias noites sem jantar, sem comer nada, eu sentia vontade de ir embora. Não, eu vou embora, eu não vou ficar aqui, eu vou embora. Mas, aí, no outro dia eu levantava com aquela vontade de ir para a faculdade de novo. Parece que, para mim, se eu perdesse aquele dia, iria piorar as coisas. E eu, mesmo com fome, sem nada para comer, para gastar, eu ia assim mesmo. Sempre fui assim, desde lá de São Jerônimo. Então, eu trouxe isso comigo, eu acho. [...] Mas isso, para mim, eu falei: - Não, eu vou levar isso até onde eu consigo levar. O dia que eu tiver me arrastando e não conseguir andar mais, aí eu paro, porque eu vejo que não dá mais. E fome, na verdade, eu posso passar fome sim, mas, talvez, um dia, não. Talvez, um dia, eu não passe fome... Na mesma hora em que eu tinha vontade de desistir dos estudos, eu via, lembrava já o que eu tinha passado. Não, mas se eu consegui chegar até aqui... (Estudante Kaingang do curso de Medicina no período dessa entrevista, atualmente matriculado no curso de Artes na UEL).

Dada a expressão de resiliência e resistência nesta inédita experiência no Paraná, a identidade cultural e política desses estudantes, potenciais lideranças e intelectuais de seus povos, passa pela compreensão da dimensão econômica e acadêmica presente nestas relações. Evidencia-se que, historicamente, as condições econômicas e materiais em que vivem os povos indígenas no Brasil e em outros países da América Latina são insuficientes e precárias, vulnerabilizando a garantia de vida digna e cidadã preconizada na legislação brasileira e nos documentos internacionais.

Além das condições objetivas para garantir a permanência dos acadêmicos indígenas, uma das íntimas faces dos fenômenos da desigualdade e da vulnerabilidade social se revela nas relações de preconceito e discriminação dentro das universidades públicas e privadas, neste caso, com as genéricas imagens e estereótipos construídos historicamente acerca dos povos indígenas. O desafio identificado com a presença dos estudantes indígenas e demais acadêmicos que se sentem estrangeiros à estrutura da universidade é que os preconceitos estão historicamente instalados nesse lugar, que se propõe ser educativo (BAIBICH, 2002; PAULINO, 2008; AMARAL, 2010). 
Assim, é possível constatar que os percursos feitos pelos acadêmicos indígenas, marcados pela insuficiência de investimentos, pelos preconceitos e pelos demais aspectos apontados nesse texto, refletem-se sobre o periférico lugar institucional ocupado pela educação superior oferecida aos povos indígenas pela política pública de educação do Paraná e do Brasil.

\section{Considerações finais}

O presente trabalho mostra o recente ingresso e permanência de acadêmicos indígenas nas IES públicas do Paraná como a emergência e efetivação de uma política pública de educação superior para os povos indígenas no território paranaense que pode ter reflexos na constituição desse direito enquanto política pública no País.

O texto constata ainda a existência do duplo pertencimento - o acadêmico e o étnico-comunitário - no processo de constituição e formação dos estudantes indígenas universitários, bem como a importância de conhecê-lo e analisá-lo para se refletir sobre as possibilidades de permanência desses sujeitos na universidade (AMARAL, 2010); porém as trajetórias relatadas e analisadas revelaram que a condição de duplo pertencimento passa a ser construída, sustentada, inventada e equilibrada por esses sujeitos pelo seu mérito próprio nesse processo formativo, pelo apoio familiar recebido, pela relação com alguns colegas e professores não indígenas e pela expectativa de sua comunidade de origem - marcada pelas relações faccionais existentes nas terras indígenas.

A falta de políticas públicas de educação superior sensíveis e coerentes com a condição diferenciada desses sujeitos e com a existência dos pertencimentos construídos por eles, fundamentais para garantir sua permanência na universidade, manifesta o vácuo existente entre a assunção individual dessa responsabilidade formativa pelos próprios acadêmicos e a responsabilidade institucional das IES envolvidas e do Estado, responsabilidade que se limita ao processo do vestibular específico e à concessão mensal da bolsa-auxílio.

A análise da iniciativa institucional paranaense de incluir estudantes indígenas no espaço acadêmico, articulada às reflexões sobre as trajetórias e experiências acadêmicas vivenciadas por esses estudantes revela alguns aspectos dos meandros e das fragilidades de uma experiência que se declara inédita enquanto ação desta natureza no cenário nacional - portanto, prenhe de possibilidades de investigações, inquietações e potencialidades. Cada lei, resolução ou ato normativo, cada edição do referido vestibular, cada vaga ofertada, cada candidato indígena inscrito, cada estudante indígena matriculado, evadido ou graduado, cada reunião de trabalho das comissões locais e estadual, cada evento científico realizado, cada projeto desenvolvido junto às comunidades indígenas, cada produção 
acadêmica elaborada e disseminada, entre outras ações relacionadas ao ensino superior dos povos indígenas do Paraná, constitui esse processo como reflexo e conquista histórica dos povos indígenas no Brasil.

Cabe às IES estaduais e ao Governo do Estado do Paraná, por meio da Secretaria de Ciência, Tecnologia e Ensino Superior, a necessária determinação de aperfeiçoar a ação afirmativa já iniciada, a qual deve tornar-se efetiva referência de interculturalidade, democracia, justiça e garantia do direito à educação. $\mathrm{O}$ aprimoramento da experiência iniciada em 2002 no Paraná e em outros estados do País requer que esta se converta em efetiva política pública, garantindo-se as condições objetivas (acadêmicas e financeiras) adequadas às necessidades e aos direitos dos sujeitos que dela demandam.

As manifestações expostas pelos entrevistados, somadas às estatísticas de evasão e conclusão apresentadas neste trabalho, revelam quão grandes são os esforços e investimentos públicos que precisam ser feitos para que o direito à educação superior realmente se efetive. Somente assim poderá ser quitada mais essa histórica dívida social para com os povos indígenas, viabilizando não somente seu acesso como uma ação afirmativa, mas também a permanência e conclusão dos seus estudos pelas portas de entrada das universidades públicas.

\section{Referências}

AMARAL, W. R. As trajetórias dos estudantes indígenas nas Universidades Estaduais do Paraná: sujeitos e pertencimentos. 2010. 2 v. 594 f. Tese (Doutorado em Educação) Universidade Federal do Paraná, Curitiba, 2010.

BAIBICH, T. M. Os Flintstones e o preconceito na escola. Educar em Revista, Curitiba, v. 19, p. 111-129, ago. 2002.

BARTH, F. Grupos étnicos e suas fronteiras. In: POUTIGNAT, P.; STREIFF-FENART, J. Teorias da etnicidade. Seguido de Grupos étnicos e suas fronteiras de Fredrik Barth. São Paulo: Editora da UNESP, 1998. p. 185-228.

BRAND, A. As experiências universitárias em curso e as propostas de trabalho. In: LIMA, A.C. S.; BARROSO-HOFFMANN, M. (Org.). Seminário Desafios para uma educação superior para os povos indígenas no Brasil: políticas públicas de ação afirmativa e direitos culturais diferenciados. Rio de Janeiro: Museu Nacional/LACED, 2007. p. 126-127.

BRASIL. Lei no. 9394/96, de 20 de dezembro de 1996. Estabelece as diretrizes e bases da educação nacional. Diário Oficial da União, Brasília, 23 dez. 1996.

. Lei no 12.416/2011, de 09 de junho de 2011. Altera a Lei no 9.394/1996, para dispor sobre a oferta de educação superior para os povos indígenas. Diário Oficial da União, Brasília, DF, 10 jun. 2011. p. 3. 
CAPELO, M. R. C.; AMARAL, W. R. Quando a diferença faz a diferença: a presença de índios na Universidade Estadual de Londrina. Educação e Linguagem, São Bernardo do Campo, v. 7, n. 10, p. 168-190, 2004.

CAPELO, M. R. C.; TOMMASINO, K. Conflitos e dilemas da juventude indígena no Paraná: escolarização e trabalho como acesso à modernidade. Cadernos CERU, São Paulo, n. 15, p. 13-33, 2004.

FELDMAN-BIANCO, B.; RIBEIRO, G. L. (Org.). Antropologia e poder. Contribuições de Eric R. Wolf. Brasília: Editora da UnB; São Paulo: Imprensa Oficial de São Paulo; Editora da Unicamp, 2003.

LIMA, A. C. de S.; BARROSO-HOFFMANN, M. (Org.). Seminário Desafios para uma educação superior para os povos indígenas no Brasil: políticas públicas de ação afirmativa e direitos culturais diferenciados. Rio de Janeiro: Museu Nacional/LACED, 2007.

MONTEIRO, S. D.; CARVALHO, M. A. V. Os estudantes indígenas da Universidade Estadual de Londrina: alguns aspectos dessa trajetória. Revista Maquinações, Londrina, v. 1, n. 2, p. 28-32, out./dez. 2008.

NOVAK, M. S. J. Política de ação afirmativa: a inserção dos indígenas nas universidades públicas paranaenses. 2007. 135 f. Dissertação (Mestrado em Educação) - Universidade Estadual de Maringá, Maringá, 2007.

As políticas da Universidade Estadual de Maringá para os estudantes indígenas.

Revista Maquinações, Londrina, v. 1, n. 2, p. 39-41, out./dez. 2008.

OLIVEIRA, R. C. de. Caminhos da identidade: ensaios sobre etnicidade e multiculturalismo. São Paulo: Editora da Unesp; Brasília: Paralelo 15, 2006.

PACHECO DE OLIVEIRA, J. Ensaios de Antropologia Histórica. Rio de Janeiro: Editora da UFRJ, 1999.

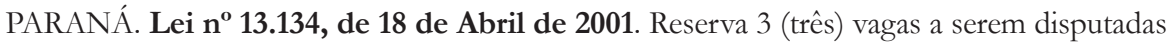
entre os índios integrantes das sociedades indígenas paranaenses, nos vestibulares das Universidades estaduais. Curitiba, 2001.

PARECI, F. N. As políticas públicas federais e a cooperação internacional para a educação superior de indígenas. In: LIMA, A. C. de S.; BARROSO-HOFFMANN, M. (Orgs.). Seminário Desafios para uma educação superior para os povos indígenas no Brasil: políticas públicas de ação afirmativa e direitos culturais diferenciados. Rio de Janeiro: Museu Nacional/LACED, 2007. p. 60-63.

PAULINO, M. M. Povos indígenas e ações afirmativas: o caso do Paraná. 2008. 140 f. Dissertação (Mestrado em Educação) - Universidade Federal do Rio de Janeiro, Rio de Janeiro, 2008.

RODRIGUES, I. C.; WAWZYNIAK, J. V. Inclusão e permanência de estudantes indígenas no ensino superior público no Paraná - reflexões. 2006. Disponível em: <http://www.acoesafirmativas.ufscar.br/relatoriocuia>. Acesso em: 15 mar. 2009. 
SILVA, R. H. D. As experiências universitárias em curso e as propostas de trabalho. In: LIMA, A. C. de S.; BARROSO-HOFFMANN, M. (Org.). Seminário Desafios para uma educação superior para os povos indígenas no Brasil: políticas públicas de ação afirmativa e direitos culturais diferenciados. Rio de Janeiro: Museu Nacional/LACED, 2007. p. 135-138.

Recebido em 28/04/2012

Versão final recebida em 30/07/2012

Aceito em 18/10/2012 